\title{
Antibiotic resistance of coagulase-negative staphylococci and micrococci
}

\author{
JEAN CORSE AND R. E. O. WILLIAMS \\ From the Wright-Fleming Institute, St. Mary's Hospital Medical School, London
}

SYNOPSIS Five hundred and seventy strains of Gram-positive, catalase-positive, coagulase+t negative cocci from various sources were classified on the basis of their ability to grow anaerojis bically and to ferment mannitol. Five groups were distinguished. The frequency of strains classified in the five groups varied with the source.

Only $26 \%$ of the strains were sensitive to all the nine antibiotics used in the tests. About halp the strains from the lesions of hospital patients were resistant to penicillin, streptomycin, and tetracycline, and about $10 \%$ of them were resistant to cloxacillin.

In general the frequency of antibiotic resistance and the 'width' of the resistance spectrum were greater in strains from hospital sources than in those from outside hospital, and they were alsक greater among strains regarded as falling in the genus Staphylococcus than in those classed as Micrococcus.

During recent years increasing interest has been shown in the coagulase-negative staphylococci and micrococci that are isolated from man. It is now known that there are circumstances in which at least some of these strains can be pathogenic for man (Quinn, Cox, and Fisher, 1965, Wilson and Stuart, 1965); it has been found that the strains isolated from hospital patients and from the hospital environment are commonly resistant to many antibiotics (Kjellander, Klein, and Finland, 1963, Kryński, Borowski, Becla, Galiński, Niemiro, Szymańska-Malottke, and Wroczyński, 1963), and some progress has been made in their classification (Baird-Parker, 1963, 1965a, 1965b). It seemed of some interest to try to bring these three lines of study in relation to one another, so we made a collection of strains from hospital patients, healthy carriers outside hospital, and air both in hospital and outside. The strains have been examined for a few physiological reactions and for antibiotic sensitivity.

MATERIAL

A total of 570 strains were studied (Table I). Of these 197 were isolated in the Diagnostic Bacteriological Laboratory here from specimens sent from pathological lesions; most of the strains had been present in abundant or pure culture and in many cases were considered

Received for publication 14 February 1968.
TABLE I

SOURCE OF STRAINS

\begin{tabular}{ll} 
Source & No. of Strains \\
\hline
\end{tabular}

Hospital patients, pathological lesions

Urinary infections

Wounds, pus

Peritoneal dialysis fluid

Sputum, eye swabs, miscellaneons from patients 36

Hospital patients, nose

$$
\text { skin }
$$

Healthy persons outside hospital, nose

Air, hospital wards

nose
skin

Air. public post offices

$\stackrel{\mathbb{D}}{\Omega}$

probably to be responsible for an infective process. The strains from healthy carriers were given to us by Di. W. C. Noble who isolated them from schoolboys and Royal Air Force personnel. The air strains were frorfr' colonies selected by a random procedure from sedimentas tion plates exposed either in the hospital wards or in two local post offices.

\section{METHODS}

All the strains were examined microscopically in Gram-stained film, and were tested for catalase produc tion on an agar slope culture and for coagulase productio by incubation overnight in broth containing $10 \%$ humaid plasma. All were catalase-positive, coagulase-negative Gram-positive cocci arranged in pairs or clusters.

The strains were stab-inoculated into tubes containin 
tryptone $1 \%$, yeast extract $0.5 \%, \mathrm{~K}_{2} \mathrm{HPO}_{4} 0.5 \%, \mathrm{NaCl}$ $0.5 \%$, agar $1.5 \%$, bromocresol purple $0.0015 \%$, and mannitol $1.0 \%$, at $p \mathrm{H} 7.0$ to 7.2 and incubated at $37^{\circ} \mathrm{C}$ for six days. These tubes were used to distinguish the facultative anaerobes from the obligate aerobes, and to determine the ability of the strains to ferment mannitol aerobically or anaerobically. Preliminary investigation showed that all the strains that were able to grow anaerobically also fermented glucose anaerobically and for this reason a separate glucose-ager stab culture was omitted.

Phosphatase production was tested by inoculation on to Oxoid nutrient agar containing $5 \%$ horse serum and $0.01 \%$ phenolphthalein diphosphate and incubated for 18 to 20 hours at $37^{\circ} \mathrm{C}$. The plates were exposed to ammonia vapour and the reaction was read as 'strong positive $(++)$ ' if a deep pink colour developed immediately, 'weak positive $(+)$ ' if the colony turned pale pink, and 'negative (-)' if it remained white.

Antibiotic sensitivity was tested with discs (Mast Laboratories or Oxoid Ltd), nutrient agar plates being inoculated with a diluted overnight broth culture to give a just-confluent lawn. Paper discs containing one of nine antibiotics (see Table IV) were then placed on the surface of the plate and the plates held at room temperature for one to one-and-a-half hours. After overnight incubation at $37^{\circ} \mathrm{C}$ the diameter of the inhibition zone was measured. One hundred and thirty-three strains were also tested by tube-dilution test for sensitivity to cloxacillin; $0.02 \mathrm{ml}$ of a diluted overnight broth culture was inoculated into $1.0 \mathrm{ml}$ volumes of series of two-fold falling dilutions of cloxacillin in nutrient broth. The diluting machine developed by Trotman (1967) proved invaluable for this purpose.

Penicillinase production was tested in the first place by adding a solution containing 1 unit of penicillin $G$ to $1.0 \mathrm{ml}$ of an overnight broth culture of the strain under test; after one hour at room temperature the fluid was pipetted into Heatley cylinders placed on a plate of nutrient agar containing a $5 \%$ concentration of a broth culture of Sarcina lutea (NCTC 8340). The plates were allowed to diffuse for one hour at room temperature before incubation at $30^{\circ} \mathrm{C}$ for 18 to 24 hours. Strains were considered to produce penicillinase when there was growth of the $S$. lutea up to the edge of the cylinder.

A small number of strains were tested for penicillinase production by an iodometric method based on that described by Perret (1954). Overnight cultures grown on nutrient agar containing $0.08 \%$ of sodium starch glycollate (BDH) were flooded with a solution containing 100 units $/ \mathrm{ml}$ penicillin G. After one hour this was replaced by a $0.01 \mathrm{~N}$ solution of iodine. Any degree of clearing around or under the colony was taken to indicate penicillinase production.

Deoxyribonuclease production was tested by stab inoculating the bacteria into a plate of medium containing Difco proteose-peptone $2 \%$, sodium chloride $0.5 \%$, Difco Bacto agar $1.5 \%$, to which was added a Seitz-filtered solution of sodium deoxyribonucleic acid (BDH) to a final concentration of $0.2 \%$. After overnight incubation at $37^{\circ} \mathrm{C}$ the plate was flooded with $\mathrm{N}$ hydrochloric acid; a clear zone around the colony was taken to indicate deoxyribonuclease production.

\section{DEFINITIONS}

The set of diagnostic tests used does not enable us to allocate the strains precisely to the detailed subdivisions described by Baird-Parker (1963, 1965a, 1965b), but we can allocate them to five groups that correspond broadly with his classification. We use the term 'Staphylococcus' to refer to the facultatively anaerobic strains. This group has three subdivisions based on mannitol fermentation. The strains that fermented mannitol anaerobically are very similar indeed to $S$. aureus but all were coagulase-negative and only one of the 16 was a strong phosphatase producer; they are conveniently termed $S$. albus. Strains that fermented mannitol aerobically but not anaerobically appear to conform with Baird-Parker's (1965a) S. epidermidis, group VI, while those that fail to ferment mannitol but can still grow anaerobically fall into his $S$. epidermidis, groups II to $\mathrm{V}$.

The strains that proved to be obligate aerobes are referred to the genus Micrococcus, those that fermented mannitol being allocated to groups 3 to 6 (Baird-Parker, 1963), while those that did not ferment mannitol are classed as Micrococcus groups 1 and 2.

\section{RESULTS}

CHARACTERISTICS OF THE $S$. albus STRAINS In view of the similarity between the 16 strains referred to as $S$. albus and coagulase-positive $S$. aureus, we examined the 13 of these strains that were still available by a series of further tests; none of the 13 produced deoxyribonuclease or haemolysin resembling the $a$-lysin of $S$. aureus, and none was sensitive to any of the standard set of $S$. aureus typing phages.

PHOSPHATASE-PRODUCTION Only 19 of the 570 strains gave a strong phosphatase reaction (Table II). It is reactions of this order that are used in the Barber and Kuper (1951) method for recognition of Staphylococcus aureus and it is apparent that false positives would have been rare among these strains. However, $73 \%$ of the $S$. epidermidis II to V strains gave a weak positive reaction. Baird-Parker's (1963) method for detecting phosphatase production involves incubation for three to five days at $30^{\circ} \mathrm{C}$ and it is probable that our 'weak positive' reactions correspond to his 'positive' reactions. He found phosphatase production to be characteristic of his $S$. epidermidis groups II and III; he also found it characteristic of his Micrococcus group 6, but in our material 'weak' phosphatase reactions were much commoner among the Micrococcus strains that did not ferment mannitol.

'SPECIES' DISTRIBUTION OF STRAINS FROM VARIOUS SOURCES The distribution of the different varieties 
TABLE II

PHOSPHATASE REACTIONS

\begin{tabular}{|c|c|c|c|c|}
\hline & \multirow{2}{*}{$\begin{array}{l}\text { No. } \\
\text { of } \\
\text { Strains }\end{array}$} & \multicolumn{3}{|c|}{ No. Giving Phosphatase Reaction } \\
\hline & & Strong & Weak & Negative \\
\hline $\begin{array}{l}\text { Staphylococcus albus } \\
\text { Staphylococcus epidermidis VI } \\
\text { Straphylococcus epidermidis II-V } \\
\text { Micrococcus } 1,2 \\
\text { Micrococcus 3-6 }\end{array}$ & $\begin{array}{r}16 \\
86 \\
253 \\
141 \\
74\end{array}$ & $\begin{array}{r}1 \\
2 \\
15 \\
0 \\
1\end{array}$ & $\begin{array}{r}4 \\
2 \\
184 \\
35 \\
2\end{array}$ & $\begin{array}{r}11 \\
82 \\
54 \\
106 \\
71\end{array}$ \\
\hline Total & 570 & 19 & 227 & 324 \\
\hline
\end{tabular}

of cocci in the material from different sources is shown in Table III and Figure 1. Almost all the 16 $(88 \%) S$. albus strains came from pathological lesions compared with $35 \%$ of the $S$. epidermidis strains and $30 \%$ of the Micrococcus strains. On the other hand, only about $7 \%$ of all the lesion strains were $S$. albus, over half of them being $S$. epidermidis and one third being Micrococcus. Among carrier strains there were very few $S$. albus and a large proportion of $S$. epidermidis. Nearly two-thirds of the air strains fell into the Micrococcus group.

RESULTS OF DISC TESTS FOR ANTIBIOTIC RESISTANCE The distributions of zone diameter observed in the disc tests with the nine antibiotics are shown in Figure 2. The shape of the distribution curves varies with the different antibiotics: tetracycline, chloramphenicol, streptomycin, erythromycin, and novobiocin showed clear bimodal distributions making the distinction of 'resistant' and 'sensitive' strains quite simple (Bauer, Perry, and Kirby, 1959). With the penicillins, kanamycin, and neomycin there were large numbers of strains showing zones of a size intermediate between those of fully resistant and obviously sensitive strains.

For the purpose of further analysis the strains were classified as sensitive, resistant, or, in the case of cloxacillin, partially resistant, on the basis of the zone diameters in the disc tests, as shown in Figure 2. The overall frequency of resistant strains is given in Table IV.

After the main part of the study had been completed 82 strains were tested for sensitivity to cephaloridine, using discs containing $5 \mathrm{mg}$ of the drug. No strain showed an inhibition zone of less than $18 \mathrm{~mm}$ and all but nine of the strains had zones greater than $24 \mathrm{~mm}$. No strain was, therefore, classed as resistant. Eighty-nine strains were similarly tested with Oxoid discs containing $10 \mu \mathrm{g}$ gentamycin or $2 \mu \mathrm{g}$ lincomycin. No resistant strains were found.

TUBE-DILUTION TESTS WITH CLOXACILLIN FOR ANTIBIOTIC RESISTANCE Particular interest attaches to the resistance to cloxacillin, so 133 strains were retested to determine the minimal inhibitory

TABLE III

FREQUENCY OF VARIOUS 'SPECIES' FROM DIFFERENT SOURCES

\begin{tabular}{|c|c|c|c|}
\hline \multicolumn{2}{|c|}{ Staphylococcus } & \multicolumn{2}{|c|}{ Micrococcus } \\
\hline \multirow[t]{2}{*}{ albus } & epidermidis & $1-2$ & $3-6$ \\
\hline & $V I$ & & \\
\hline
\end{tabular}

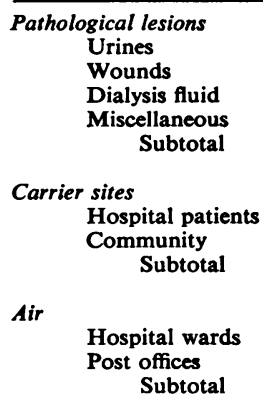




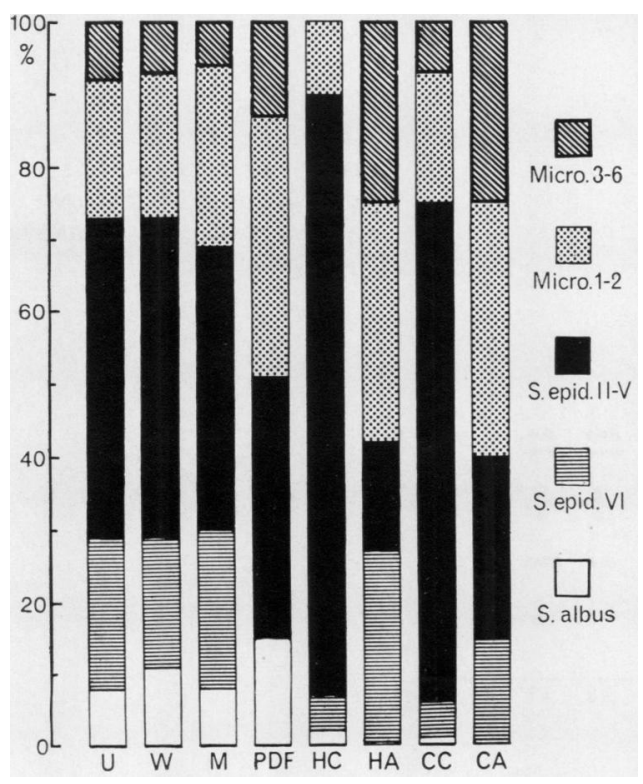

FIG. 1. 'Species' distribution among strains from different sources. $U=$ urine; $W=$ wounds; $M=$ miscellaneous pathological specimens; $P D F=$ peritoneal dialysis fluid; $H C=$ carrier sites in hospital patients; $H A=$ hospital air; $C C=$ carrier sites in healthy persons outside hospital; $C A=$ air outside hospital. For definition of 'species', see text.
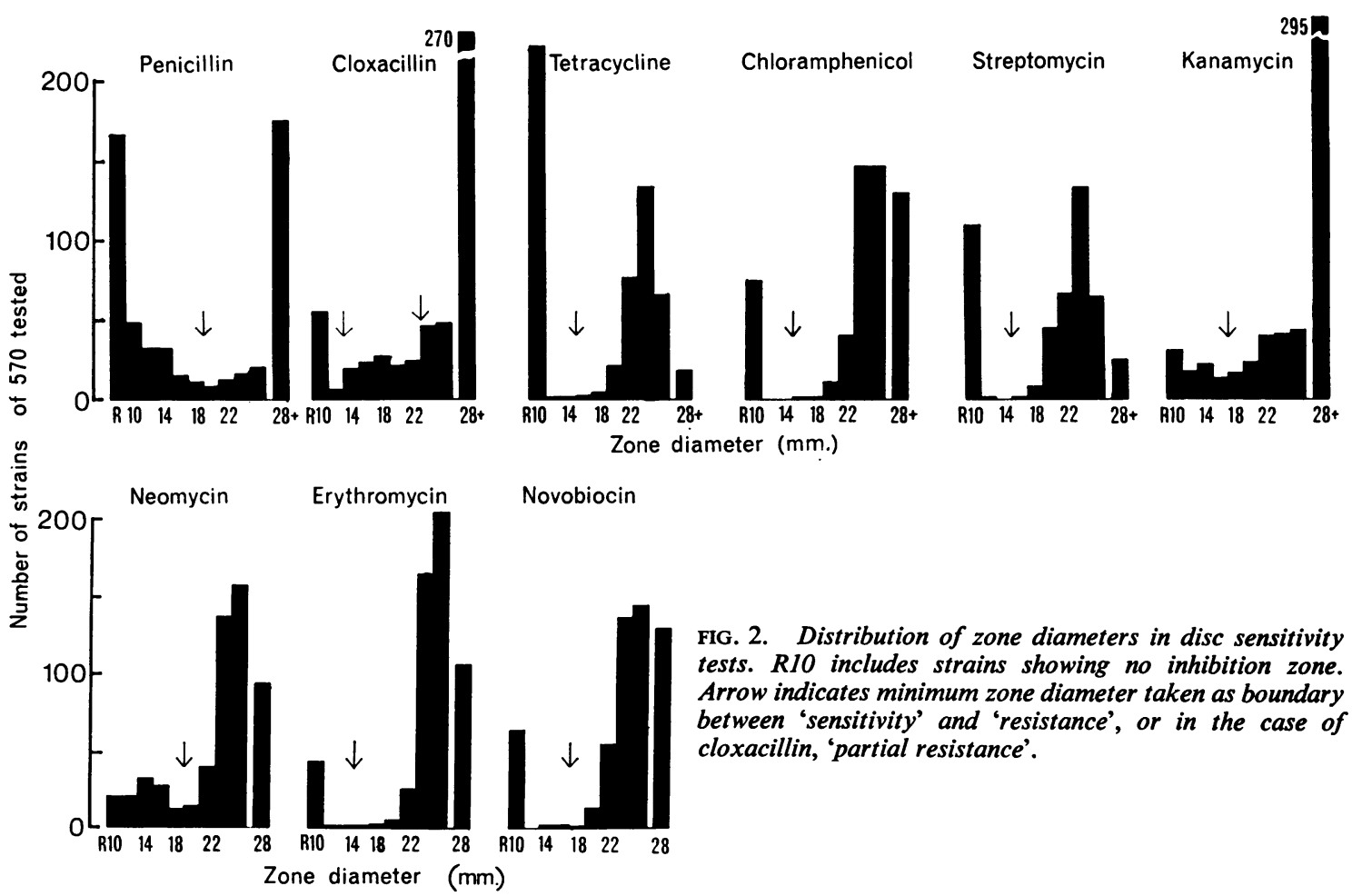

FIG. 2. Distribution of zone diameters in disc sensitivity tests. R10 includes strains showing no inhibition zone. Arrow indicates minimum zone diameter taken as boundary between 'sensitivity' and 'resistance', or in the case of cloxacillin, 'partial resistance'. 


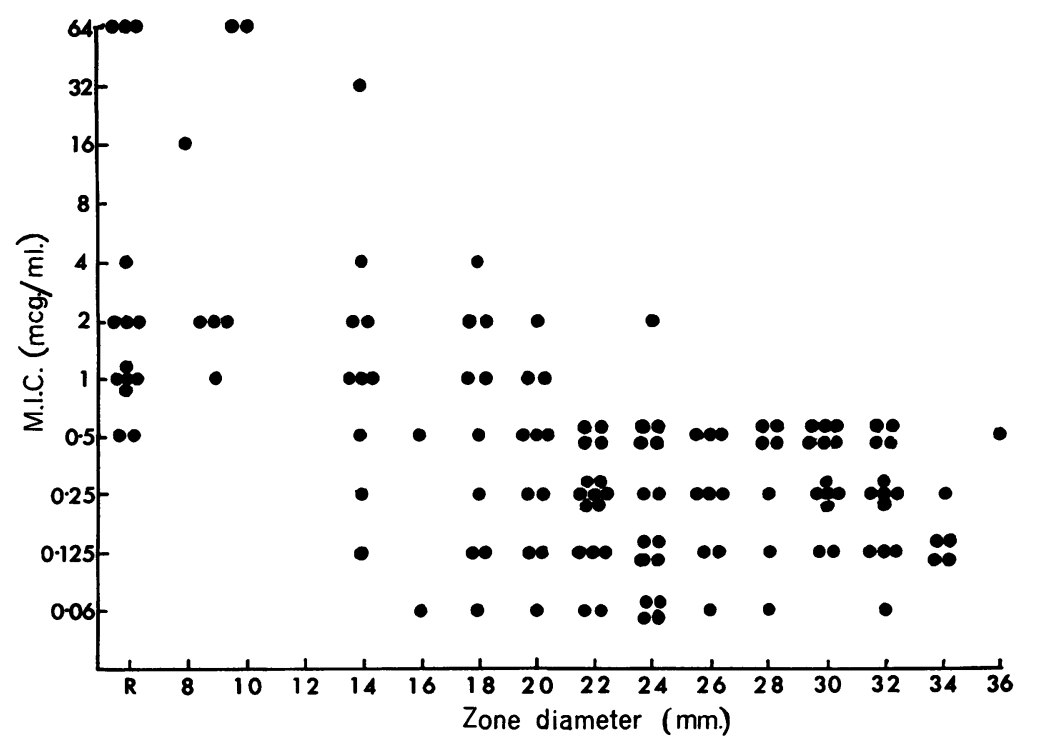

FIG. 3. Relation of MIC for cloxacillin to inhibition zone diameter round discs containing $5 \mu \mathrm{g}$ cloxacillin.

less. There are clearly, by both methods of testing, a number of strains of intermediate sensitivity.

ANTIBIOTIC RESISTANCE IN RELATION TO SOURCE AND 'SPECIES' The $S$. albus strains, which were almost all from lesions, were all resistant to one or more antibiotics and $19 \%$ of them were resistant to cloxacillin (Table V). Among the other 'species' the strains from hospital sources were in all cases more frequently resistant than those from extrahospital sources (Fig. 4). In general the Micrococcus strains were less often resistant than the Staphylococcus strains. Complete resistance to cloxacillin was very rare in strains isolated from carriers or air but it was notable that strains partially resistant to cloxacillin were common among all varieties and from all sources.

In contrast to the experience of Alder, Brown, and
Mitchell (1966) resistance to novobiocin was observed among strains from all the 'species?, being commoner in those classed as $S$. epidermidit VI $(22.1 \%)$ and Micrococcus 3 to $6(21.6 \%)$ than in the others.

PENICILlinase PRODUCTION The results of the tests for penicillinase are set out in Table VI. In general there was good correlation of penicillio resistance with penicillinase production though there were some anomalous results. Twenty-thres strains produced penicillinase although they had appeared sensitive in disc tests. Repetition of the disc sensitivity tests on these strains confirmed the original result in all cases. It was possible to retest only seven of these strains by the iodometric methoe but all were penicillinase-positive. They were not strains with borderline inhibition zones. Of 18

TABLE $V$

ANTIBIOTIC SENSITIVITY IN THE VARIOUS 'SPECIES'1

\begin{tabular}{|c|c|c|c|c|c|c|}
\hline \multirow{3}{*}{ Antibiotic Resistance } & \multicolumn{6}{|c|}{ Percentage of Strains } \\
\hline & \multicolumn{3}{|c|}{ Staphylococcus } & \multicolumn{2}{|c|}{ Micrococcus } & \multirow[t]{2}{*}{ Total } \\
\hline & albus & epidermidis $V I$ & epidermidis other & $1-2$ & $3-6$ & \\
\hline $\begin{array}{l}\text { None } \\
\text { Penicillin G only } \\
\text { Penicillin G, streptomycin, and tetracycline } \\
\text { Pen., strep., tet., and cloxacillin } \\
\text { Cloxacillin } \\
\text { Cloxacillin, partial resistance }\end{array}$ & $\begin{array}{r}0 \\
0 \\
88 \\
19 \\
19 \\
63\end{array}$ & $\begin{array}{r}10 \\
3 \\
52 \\
35 \\
35 \\
30\end{array}$ & $\begin{array}{r}29 \\
20 \\
22 \\
2 \\
5 \\
12\end{array}$ & $\begin{array}{r}31 \\
9 \\
20 \\
1 \\
3 \\
17\end{array}$ & $\begin{array}{r}27 \\
8 \\
22 \\
0 \\
0 \\
28\end{array}$ & $\begin{array}{r}26 \\
12 \\
28 \\
7 \\
9 \\
19\end{array}$ \\
\hline No. of strains & 16 & 86 & 253 & 141 & 74 & 570 \\
\hline
\end{tabular}

${ }^{1}$ The figures give the total percentage of strains with the stated resistance pattern, so the columns do not total $100 \%$ 


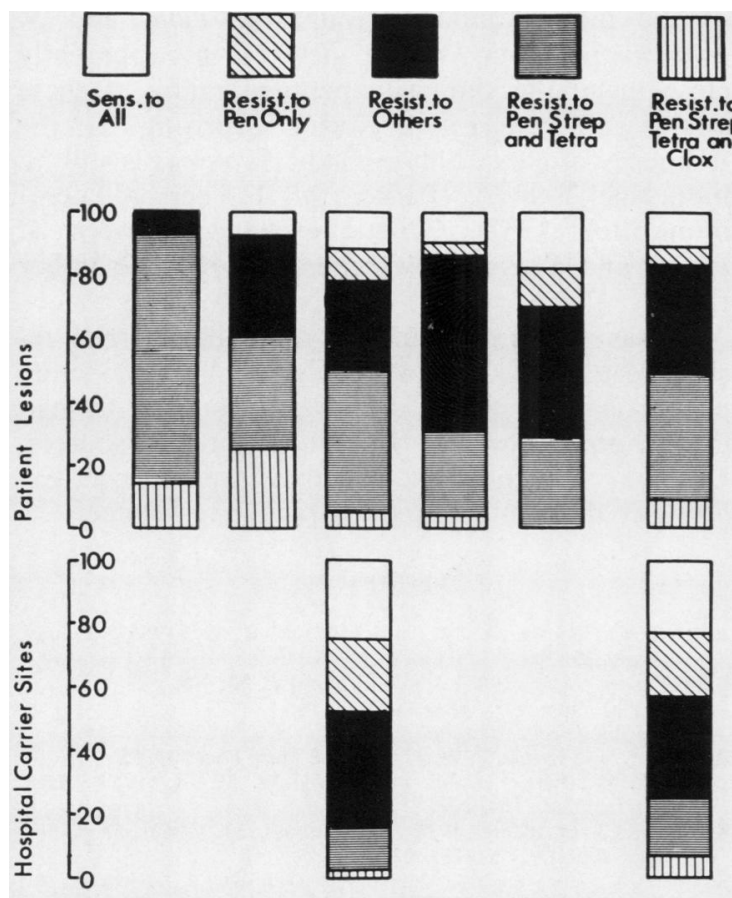

FIG. 4. Antibiotic sensitivity of strains in the various 'species' from different sources.

resistant strains that did not appear to produce penicillinase by the Sarcina lutea test only one was available for retesting and it was shown to be a weak penicillinase producer by the iodometric test.

\section{DISCUSSION}

The coagulase-negative staphylococci have been neglected by medical bacteriologists in the past, doubtless largely because the very great majority of pyogenic lesions are associated with infection by coagulase-positive strains, and partly because of the

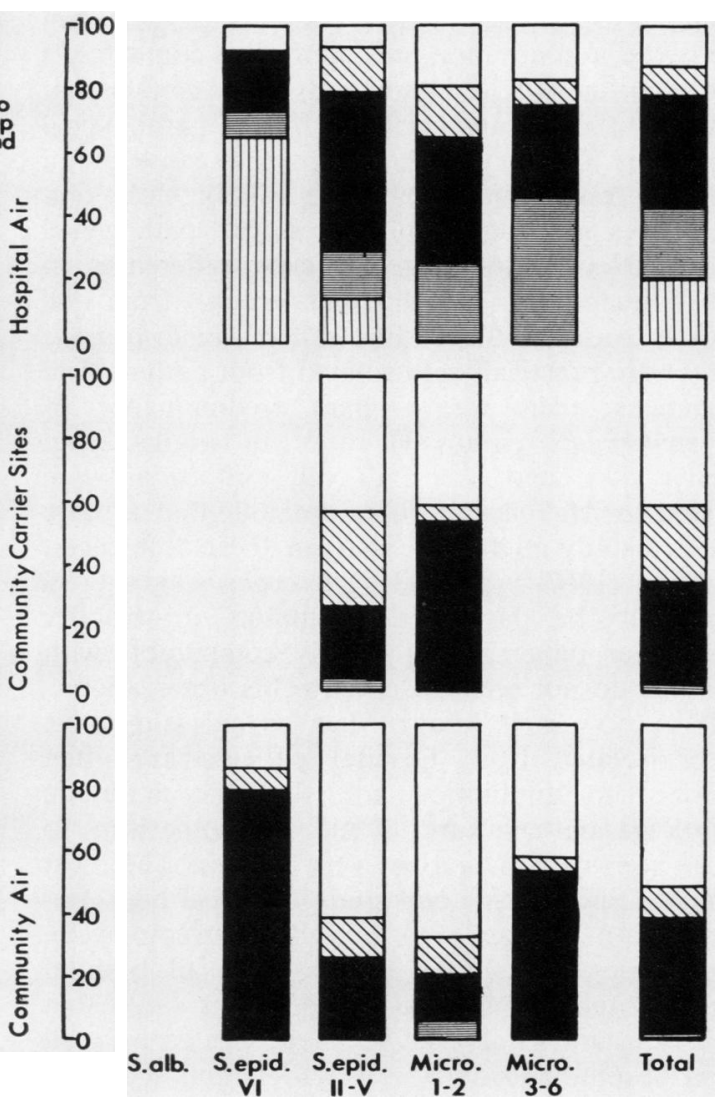

lack of any accepted criteria for distinguishing the seemingly numerous varieties of coagulase-negative cocci. It is fortunate that Baird-Parker's (1963, 1965a, 1965b) taxonomic studies have appeared at a time when it is becoming evident that some coagulase-negative cocci, at least, can cause disease in man. The present paper reports some preliminary studies aimed to discover whether Baird-Parker's broad categories appeared to be of use in investigating cocci of medical interest.

It is notoriously difficult to judge whether an infecting organism is, in some particular case,

TABLE VI

PENICILLINASE PRODUCTION (S. lutea TEST) ${ }^{1}$

\begin{tabular}{|c|c|c|c|c|c|}
\hline \multirow[b]{3}{*}{$\begin{array}{l}\text { Sensitive to penicillin } \mathbf{G} \text { and other antibiotics tested } \\
\text { Sensitive to penicillin } \mathbf{G} \text {; resistant to some antibiotics } \\
\text { Total sensitive to penicillin } \mathbf{G} \\
\text { Resistant to penicillin } \mathbf{G}\end{array}$} & \multirow{2}{*}{$\begin{array}{l}\text { No. of } \\
\text { Strains }\end{array}$} & \multicolumn{4}{|c|}{ No. and Percentage } \\
\hline & & \multicolumn{2}{|c|}{$\begin{array}{l}\text { Producing } \\
\text { Penicillinase }\end{array}$} & \multicolumn{2}{|c|}{$\begin{array}{l}\text { Not Producing } \\
\text { Penicillinase }\end{array}$} \\
\hline & $\begin{array}{r}148 \\
80 \\
223 \\
331\end{array}$ & $\begin{array}{r}5 \\
18 \\
21 \\
321\end{array}$ & $\begin{array}{l}(3.4 \%) \\
(22.5 \%) \\
(9.4 \%) \\
(97.0 \%)\end{array}$ & $\begin{array}{r}143 \\
62 \\
202 \\
10\end{array}$ & $\begin{array}{l}(96.6 \%) \\
(77.5 \%) \\
(90.6 \%) \\
(3.0 \%)\end{array}$ \\
\hline
\end{tabular}

'Eleven strains were lost before testing. 
acting as a pathogen, and this is especially so when the bacteria in question are common as commensals and environmental contaminants. It is certain that not all the strains isolated from pathological specimens in our studies were the cause of an infective lesion but, even so, it will be clear that there does not appear to be a single 'pathogenic' species. Nevertheless there are clear differences in the frequency of the different groups from the various sources: the strains called Staphylococcus albus were practically all isolated from pathological specimens; there was a great predominance of $S$. epidermidis groups II to $\mathrm{V}$ in strains from carrier sites, and over half the air strains were classed as Micrococcus. It is probable that a more detailed study might well sharpen these differences. Roberts (1967) reported Micrococcus group 3 strains to be particularly common in bladder urine; our data are not strictly comparable with this but do not seem to confirm his observations.

It is now well known that coagulase-negative cocci isolated from hospital patients are often resistant to antibiotics, and that the antibiotic resistance patterns are often, in comparison to those seen with $S$. aureus, very bizarre. The most striking findings in our study are the high frequency of resistance to penicillin, streptomycin, and tetracycline among strains from all hospital sources, and the finding of 51 strains $(9 \%)$ that were resistant to cloxacillin. These strains were all from hospital sources and were commonest in two of the five taxonomic groups-S. albus and $S . \stackrel{ }{\circ}$ epidermidis, group VI. In view of the apparently $\overrightarrow{\vec{F}}$ close metabolic similarity between many of these $\frac{?}{0}$ strains and $S$. aureus, it is very surprising that the frequency of cloxacillin-resistant $S$. aureus is still no $\frac{\bar{m}}{\frac{\mathrm{N}}{D}}$ more than 1 to $2 \%$ (Parker, M. T., personal com- $\widehat{\mathbb{D}}$ munication, 1967). Genetic exchange between $S$. ㅇ aureus and $S$. epidermidis must, happily, be rather $\omega$ rare.

It was also interesting to note that partial re- $\overrightarrow{-}$ sistance to cloxacillin was observed in a moderate $\vec{\rho}$ proportion of strains of all species and, though this is not shown in Fig. 4, from all sources. Evidently the coagulase-negative staphylococci ex- $-\overrightarrow{-}$ hibit two different forms of cloxacillin resistance.

\section{REFERENCES}

Alder, V. G, Brown, A. M. and Mitchell, R. G. (1966) J. appl. Bact., 29, 304.

Baird-Parker, A. C. (1963). J. gen. Microbiol., 30, 409.

(1965a). Ann. N.Y. Acad. Sci., 128, 4.

_- (1965b). J. gen. Microbiol., 38, 363.

Barber, M., and Kuper, S. W. A. (1951). J. Path. Bact., 63, 65.

Bauer, A. W., Perry, D. M., and Kirby, W. M. M. (1959). Arch. 므 intern. Med., 104, 208.

Kjellander, J. O., Klein, J. O., and Finland, M. (1963). Proc. Soc. $\overrightarrow{\mid}$ exp. Biol. (N.Y.), 113, 1023.

Kryński, S., Borowski, J., Becla, E., Galiński, J., Niemiro, A., Szymańska-Malottke, R., and Wroczyński, M. (1963). Amer. J. Hyg., 78, 111.

Perret, C. J. (1954). Nature (Lond.), 174, 1012.

Quinn, E. L., Cox, F. and Fisher, M. (1965). Ann. N.Y. Acad. Sci., $128,428$.

Roberts, A. P. (1967). J. clin. Path., 20, 631.

Trotman, R. E. (1967). Ibid., 20, 770.

Wilson, T. S., and Stuart, R. D. (1965). Canad. med. Ass. J., 93, 8. 